\title{
An Instrument to Measure Math Attitudes of Computer Science Students
}

\author{
Parveen J. Ali, Sanwar Ali, and Waleed E. Farag
}

\begin{abstract}
Although mathematics is one of the essential courses for students in determining college majors, for many students in postsecondary education, mathematics is seen more as a frightening ordeal than a valuable learning experience. Computer science students explicitly use mathematics in many computer science courses. This demands that computer science majors have in-depth math background to become successful in a computer science career. This paper is a report of the initial development of a new instrument to measure computer science students' attitudes towards mathematics. The reliability coefficient, Cronbach alpha value, for the instrument in our study is found to be 0.811 and coefficients for four subscales are ranged from 0.812 to 0.915 . These values seem to be very promising for this study.
\end{abstract}

Index Terms - Cronbach coefficients, enjoyment of math, math anxiety, math attitude, math relevancy, self-efficacy, survey instrument

\section{INTRODUCTION}

For many students in postsecondary institutions, mathematics is seen more as a frightening course than a valuable learning experience. However, mathematics is one of the essential courses for students in determining college majors. Most computer science (CS) courses are taught by using mathematics. Deficiencies in mathematical knowledge may impede students' success in CS courses. Attitude significantly affects learning [1]. Surprisingly, few studies are available on the impact of attitude towards mathematics and performance of CS students.

Students who come to higher education to study computer science often feel math is not core to their learning experience. However, mathematics is used to introduce students to a variety of theoretical issues in computer science [2]. Research has demonstrated that good mathematical knowledge is central to computer science education. "...mathematics is a mindset that fundamentally improves one's ability to devise and implement algorithms. Mathematics is used to model the problem domain, to specify and design high quality software, develop correct and efficient algorithms" [3]. Most computer science textbooks are written in formal mathematical languages. Poor mathematical skills jeopardize students' ability to learn, understand and appreciate fundamental theories of computer science.

Attitude significantly affects learning in general [1] and [4]. Attitude is not directly observable but can be defined in

Manuscript received October 2, 2013; revised December 23, 2013.

The authors are with Indiana University of Pennsylvania, Indiana, USA (e-mail: pali@iup.edu, sanwar@iup.edu,farag@iup.edu). many ways. Definitions of attitude generally combine behaviors as well as thoughts and feelings. One definition of attitude includes "thoughts, feelings, and behaviors" [5]. Similarly, Triandis [6] described attitude as how people think about, feel about, and act towards an object. There are several qualities that can fall under the term attitude, including self-efficacy, study strategies, motivation, confidence, anxiety, and enjoyment [4].

\section{LITERATURE REVIEW}

An extensive search revealed numerous papers and articles on math attitude. However, these publications are primarily based on the research conducted on elementary and secondary students' math attitudes. Few publications were found involving college and university students' or the math attitudes of CS majors.

Wiebe et al. [7]conducted a survey to measure CS students' attitudes towards computer programming and computer science in general. Their survey instrument consists of 57 questions with positive and negative statements. The negative statements were reversed prior to summing the subscales scores. They evaluated their instrument for internal consistency of the five subscales: confidence in learning CS \& programming, attitude toward success in CS, CS as a male domain, usefulness of CS \& programming, and the effective motivation in CS \& programming. The Cronbach's Alpha values for these subscales ranged from 0.83 to 0.91 .

Hoegh and Moskal [8] conducted an interesting study concerning science and engineering students' attitudes toward computer science. The focus of their study was to develop and validate a survey that would measure undergraduate student perceptions of computer science in science and engineering fields. In their computer science attitude survey, Hoegh and Moskal identified five subscales: confidence, interest, gender, usefulness, and profession in $C S$; and Cronbach's Alpha values of these subscales were greater than 0.7 .

Paulson [3] studied the effectiveness of a strong mathematical background in learning and understanding theoretical courses of computer science, particularly the Theory of Computation. Her study concluded that " $19.6 \%$ of students had a decrease of two letter grades" and " $41.3 \%$ of students had a decrease of one letter grades" than their average grade in other CS courses because of insufficient training in mathematics.

Baldwin and Henderson [9] and Henderson [10] strongly argued for the importance of mathematics to software engineering and its practitioners. "Software engineering is an emerging discipline that applies mathematical and 
computer science principles to the development and maintenance of software systems. It relies primarily upon principles of discrete mathematics, especially logic" [10]. Henderson continues to argue that "Mathematics is requisite for modeling software systems" and "Mathematical reasoning about software system is essential". A software developer may not explicitly use math, but they use math implicitly. On the contrary, a computer scientist always uses math explicitly. To become a successful computer scientist, a CS student must have in-depth knowledge, particularly in discrete math, data structures, and algorithm analysis. Discrete Mathematics (also known as Discrete Structure) is commonly taught by CS faculty. In our university, it is taught in the math department. A Data Structures \& Algorithms course is taught in the CS department. All CS majors must complete these two courses to earn their bachelor degrees at our university.

Konvalina et al. [11] compared students who successfully completed a first CS course to students who withdrew from the course. They observed that the students who had good background in mathematics in their secondary and postsecondary education performed well in this first CS course. Wilson and Shrock [12] "correlated midterm exam scores in an introductory CS courses to 12 possible success predictors" and "found that high school math back-ground was the second-most important predicator". Byrne and Lyons [13] conducted research in Ireland to examine the relationship between students' performance in a first year programming course and their math background. This study indicated a clear correlation between students' programming ability and their math aptitude. Tay [14] published an interesting paper, "What should Computer Science students learn from Mathematics?"where he discussed the application of math in advanced topics of computer science, such as computational complexity, public key encryption, and cryptanalysis to name a few.

Recently, Tekerek et al. [15] conducted a broader research on math attitudes of computer education and instructional technology students in Turkey. In their study, they investigated a number of variables, such as type of graduated high school, GPA in high school diploma, YGS score (i.e., transition to higher education examination, equivalent to SAT score in USA), gender, parents' education level, and grades in IT and in math courses that could affect students' attitudes towards math. The Cronbach's alpha coefficient of the scale for their study was found to be 0.96 .

The principle focus of the present research was to develop an efficient instrument that would measure computer science students' attitudes toward mathematics and its usefulness to learn computer science effectively.

\section{Methodology}

\section{A. Participants}

The sample consisted of 22 students who enrolled in COSC310 Data Structures\& Algorithms, one of the sophomore/junior level core courses for undergraduate CS majors at a mid-sized state university in western
Pennsylvania in spring 2013.The reason for choosing this course follows. The course discusses fundamental concepts of data design and implementation, data abstraction, various data structures like arrays, linked-lists, stacks, queues, recursion, trees, graphs, and hashing. The course continues to discuss various sorting algorithms, divide and conquer techniques, greedy approaches, and analysis of algorithms. These topics are essential for CS students to become successful computer scientists and software developers as well. To grasp clear knowledge of these topics, particularly of algorithms, students must have sound concepts in mathematics. As Knuth [16] says, "An algorithm is a precisely-defined sequence of rules telling how to produce specified output information from given input information in a finite number of steps. A particular representation of an algorithm is called a program ......".

The gender composition of the sample was 20 male (91\%) and two female (9\%) students. The mean age of the participants was 21 years $(\mathrm{SD}=3.58)$. Approximately, $64 \%$, $27 \%$ and $9 \%$ were sophomore, junior and senior, respectively. The race distributions of the class sample were: $76 \%$ white, $14 \%$ African-American, and 10\% Asian. This study was approved by the Institutional Review Board of the University for the Protection of human subjects.

\section{B. Instrument}

The survey instrument was carefully designed. It consists of 40 questions about attitudes towards mathematics of CS majors who are enrolled in a sophomore/junior level computer science course in a U.S. public university, along with some demographic information. In addition to answering survey questions, students signed consent forms giving permission to the researchers to administer the survey. Responses were measured with Likert-type items consisting of 10 response options ranging from "do not agree at all" to "strongly agree." The higher score means a more positive attitude towards mathematics with the exception of five negatively worded questions that show a lower score to indicate a more positive attitude. The negative statements were reverse coded prior to calculate the Cronbach's alpha coefficient. From these 40 questions, four different subscales of math attitude were constructed for analysis. These four subscales are: self-efficacy, enjoyment of math, math anxiety, and math relevancy.

\section{RESUlTS}

The Cronbach's alpha is commonly used to find a scale's internal consistency. This coefficient of a scale, ideally, should be above 0.7 [17]. First, the reliability of our math attitude scale was tested indicating good reliability and internal consistency of the instrument. The Cronbach's alpha coefficients for the survey instrument and for the four subscales were computed using SPSS Version 20 software and they are shown in Table I. The Cronbach's alpha value for the instrument in our study is found to be 0.811 and for the four subscales range from 0.812 to 0.915 . We also constructed another subscale called Study Skills, using the remaining six questions, but its Cronbach's alpha was found to be very low. Therefore, we removed this subscale from our instrument. 
TABLE I: AlPHA RELIABILITIES FOR SUBSCALES OF MATH ATTITUDE

\begin{tabular}{|c|c|c|}
\hline Subscales & Questions & Cronbach's Alpha \\
\hline Self-Efficacy (SE) & $\begin{array}{l}\text { - I have confidence in my mathematics ability } \\
\text { - I feel that I have learned good math concepts from the math courses that I have taken so } \\
\text { far. } \\
\text { - I have forgotten many of the math concepts that I learned from past math courses. } \\
\text { - I can apply a wide variety of mathematical techniques to solve a particular problem. } \\
\text { - I believe that I can learn from my mistakes. } \\
\text { - I believe doing homework and asking questions in class can improve my math ability. } \\
\text { - I believe that I will do well in a math course if I have a good math teacher. } \\
\text { - When math work is hard, I usually give up. }\end{array}$ & 0.812 \\
\hline Enjoyment (E) & $\begin{array}{l}\text { - I enjoy doing math. } \\
\text { - Math word problems fascinate me. } \\
\text { - I always look forward to a math class. } \\
\text { - Math is very interesting to me. } \\
\text { - I enjoyed watching a teacher work on a math problem on the board. } \\
\text { - I think of other things when a math teacher is talking or working on a problem. } \\
\text { - I also like to do and think about math outside of school. } \\
\text { - Math is boring. }\end{array}$ & 0.883 \\
\hline Anxiety (A) & $\begin{array}{l}\text { - My mind goes blank when I see a math test. } \\
\text { - I feel uneasy when I see word problems. } \\
\text { - I feel nervous when a math teacher asks me questions in class. } \\
\text { - I feel insecure about asking math questions in class. } \\
\text { - Iget nervers frightened } \\
\text { - When I take a math test, I worry that I will get a bad grade. } \\
\text { - I worry a lot before a math test. }\end{array}$ & $\begin{array}{c}0.897, \text { original } \\
\text { (0.914, after removing } \\
\text { one question indicated } \\
\text { as strike through) }\end{array}$ \\
\hline Relevance (R) & $\begin{array}{l}\text { - Math classes provide the opportunity to gain knowledge that is useful in real life. } \\
\text { - Understanding math is important to me as a computer science major. } \\
\text { - Math helps people to make good decisions. } \\
\text { - Math is very important for computer science. } \\
\text { - Without good mathematical ability, it is very difficult to understand computer science } \\
\text { - courses. } \\
\text { - Improved math skills are not important in a computer science career. } \\
\text { - Good mathematical knowledge makes it easier to learn computer science courses. } \\
\text { - A cood mathematician can be a good computer scientist. } \\
\text { - Strong math background helps in writing good computer programs. } \\
\text { - Good skills in mathematics will help me to earn a better salary. }\end{array}$ & 0.915 \\
\hline
\end{tabular}

\section{DISCUSSIONS}

This paper reports on the initial research efforts that have been used in the development of an instrument to measure computer science students' attitudes toward mathematics. We tested the reliability of students' math attitudes scale and found good reliability and internal consistency of the instrument using SPSS Version 20. The Cronbach's alpha value for the instrument in our study is found to be 0.811 . Also, the Cronbach's Alpha coefficients for the four subscales range from 0.812 to 0.915 . These alpha values assert that we have successfully developed an efficient instrument for our study. We will continue to collect data during fall 2013 and spring 2014 to increase the sample size to 100 . We will then find whether there is a correlation between students' math attitudes and performances in Data Structures \& Algorithms course. The performance will be measured by matching students' final semester grades in the course.

\section{REFERENCES}

[1] M. S. Fadali, N. Valasquez, and M. Robinsoon, "Work in progress- is attitude toward mathematics a major obstacle to engineering education?" presented at the 34th ASEE/IEEE Frontiers in Education Conference, 2004.

[2] P. Gregory, "Motivating computing students to learn mathematics," MSOR Connections, vol. 4, no. 3, pp. 26-28, 2004.

[3] H. G. Paulson. (2002). Computer Science Students Need Adequate Mathematics Background. [Online]. Available: http://www.math.uoc.gr/ ictm2/Proceedings/pap398.pdf

[4] P. Ali and S. Dawkins, "Math attitude and performance in college," Academic Exchange Quarterly, pp. 75-81, summer, 2010.
[5] K. Kislenko, B. Grevholm, and M. Lepik, "Mathematics is important but boring: Students' beliefs and attitudes towards mathematics," in Relating practice and research in mathematics education. Proceedings of NORMA 05, C. Bergsten, B. Grevholm, H. S. Masoval, and F. Ronning, Eds, Trondheim, Norway: Tapir Academic Press, 2007, pp. 349-360.

[6] H. C. Triandis, Attitude and attitude change, New York, NY: Wiley, 1971.

[7] E. N. Wiebe, L. Williams, K. Yang, and C. Miller. (2003). Computer Science Attitude Survey. [Online]. Available: http://www4.ncsu.edu/ wiebe/www/articles/prl-tr-2003-1.pdf

[8] A. Hoegh and B. M. Moskal, "Examining Science and Engineering Students' Attitudes Toward Computer Science" in Proc. the $39^{\text {th }}$ ASEE/IEEE Frontiers in Education Conference, San Antonio, TX, October 2009.

[9] D. Baldwin and P. B. Henderson, "The Importance of Mathematics to the Software Practitioners," IEEE Software, March/April Issue, pp. 13, 2002.

[10] P. B. Henderson, "Mathematical Reasoning in Software Engineering Education," Communications of the ACM, vol. 46, no. 9, pp. 45-50, September 2003.

[11] J. Konvalina, S. Wileman, and L. J. Stephens, "Math Proficiency: A Key to Success for Computer Science Students," Communications of the ACM, vol. 26, no. 5, pp. 377-382, 1983.

[12] B. Wilson and S. Shrock, "Contributing to Success in an Introductory Computer Science Course: A study of Twelve Factors" in Proc. the $32^{\text {nd }}$ SIGCSE Technical Symposium on Computer Science Education, 2001, pp. 184-188.

[13] P. Byrne and G. Lyons, "The Effect of Student Attributes on Success in Programming," in Proc. the $6^{\text {th }}$ Annual Conference on Innovation and Technology in Computer Science Education, 2001, pp. 49-52.

[14] Y. C. Tay, "What should Computer Science students learn from Mathematics?" Communications of the ACM, SIGACT News, vol. 36, no. 2, pp. 131-143, 2005.

[15] M. Tekerek, B. Yeniterzi, and O. Ercan, "Math Attitude of Computer Education and Instructional Technology Students," The Turkish Online Journal of Educational Technology, vol. 10, no. 3, pp. 168174, 2011. 
[16] D. E. Knuth, "Computer Science and its Relation to Mathematics", inThe American Mathematical Monthly, vol. 81, no. 4, pp. 323-343. April 1974.

[17] J. Pallant, SPSS Survival Manual (4/e), Open University Press, New York, NY: McGraw-Hill, 2010.

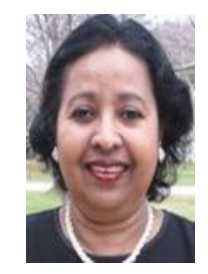

Parveen J. Ali is an associate professor in the Department of Developmental Studies at Indiana University of Pennsylvania, Indiana, PA 15705, USA. She holds an M.S. in physics and D.Ed in curriculum and instruction from the United States. Dr. Ali has extensive experience in various levels of math teaching and in curriculum development. Her research interests include math education, genderequity, diversity, and religion.

Dr. Ali has published a book and several journal and conference proceeding papers. She also served as a reviewer for several journals. In her early career, Dr. P. Ali taught mathematics for nearly 13 years in secondary schools and seven years in colleges in the Unites States.

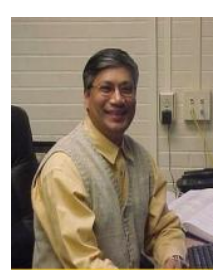

Sanwar Ali is a full professor in the Department of Computer Science at Indiana University of Pennsylvania, Indiana, PA 15705, USA. He holds an M.S. and PhD in physics and an M.S. in computer science from the United States. He also completed a postdoctoral fellowship in electrical engineering for two years. During his early career, Dr. Ali taught physics and engineering. For the last 18 years, he has been teaching a wide range of undergraduate computer science courses. Dr. Ali's research interests include the application of cryptography in ecommerce, mobile commerce, quantum cryptography, and computer education. He has published several journal and proceeding papers. Dr. S. Ali has been serving as a member of technical program committees and a reviewer for several international conferences.

Waleed E. Farag is a full professor in the Department of Computer Science at Indiana University of Pennsylvania, Indiana, PA 15705, USA $\mathrm{He}$ holds a $\mathrm{PhD}$ in computer science from the United States. He also earned an M.S. in electrical engineering from Egypt. He has been teaching a wide range of undergraduate computer science courses. Dr. Farag's research interests include e-learning and its assessment strategies, multimedia access and retrieval techniques, and multimedia data security and information hiding. He has numerous publications in his areas of interest. Furthermore, Dr. Farag is serving in the technical program committees and as a reviewer for several international journals and conferences and he is a member of the ACM. 